\title{
APROXIMACION AL CONOCIMIENTO DEL BADAJOZ ROMANO
}

Jesús Cánovas Pessini

Fernando Valdés Fernández

Deshechada hace ya muchos años la teoría que identificaba la Pax Augusta de los romanos con la actual Badajoz, la existencia en este lugar de algún tipo de poblamiento, en los primeros siglos de la era cristiana, quedó convertida en mero terreno de especulación e hipótesis, más o menos fundadas.

Resultaría vano entrar de nuevo en una polémica poco clarificadora, fundada, desde sus comienzos, en elementos históricamente muy confusos.

Ahora bien, si las fuentes escritas adolecen de poca claridad, no ocurre lo mismo con las arqueológicas. No puede asegurarse, al menos por el momento, que éstas sean todo lo prolijas e incuestionables que desearíamos; sin embargo, son, por ahora, el único elemento cierto de juicio al que puede atenerse cualquier opinión favorable a la existencia de una población romana en lo que hoy es ciudad de Badajoz.

La campaña de excavaciones arqueológicas llevada a cabo en la $\mathrm{Al}$ cazaba de esta ciudad durante el verano de 1978 — segunda de las allí efectuadas- comenzó a aportar algunos datos más substanciosos que los habidos hasta el presente.

Pudimos constar durante su transcurso la presencia de unos muros cuyo tipo de construcción nos parece muy característico (láminas I y II). Efectivamente, los cortes 10 y 11 fueron abiertos a extramuros del recinto de la fortificación, a escasísima distancia de la carretera de circunvalación de la ciudad, enfilando las primeras casas del barrio de San Roque. Su primera intención era aclarar algo acerca de la naturaleza de una construcción no demasiado grande, de la que arranca, en dirección sur, una pared con contrafuertes. A su vez, este ámbito - son muy grandes las dudas acerca de su funcionalidad concreta- sirve de base a un largo lienzo de muralla que arranca a pocos metros de la Puerta del Alpendiz y va a morir justamente encima de él, recorriendo, perpendicularmente al recinto, la rápida pendiente de la falda del cerro. 
Si la naturaleza de esta construcción resulta bastante misteriosa, por lo inopinado de su presencia en ese lugar, más extraña es aún la edificación que aparenta rematarlo, dadas las evidentes diferencias constructivas que los distinguen.

Mientras el lienzo que desciende de la muralla del recinto, del cual se evidencian sin soterrar algunos paños de bastante consideración, tiene las mismas características arquitectónicas que el resto del recinto almohade de la fortaleza, la construcción final y la pared a la que ésta da origen están realizados en un tipo de argamasa radicalmente diferente, muy parecida en sus características al hormigón romano u opus caementicum (1). Por otra parte, ateniéndonos siempre a uno análisis estrictamente formal de los elementos constructivos, ambos tipos de edificación son diferentes a los empleados en la fortificación Vauban, fundada a fines del siglo XvII, que cerca la plaza.

Desde una óptica arqueológica, no parece haber dificultad en considerar medieval el largo muro que surca la falda del cerro (2), atribuyendo al otro una fecha más antigua. Sin embargo, los hallazgos arqueológicos, asociados al que, hipotéticamente, consideramos de época romana, son aún demasiado parcos como para establecer dataciones certeras por otro método que no sea el estrictamente comparativo.

También ha aportado algún detalle cronológico la aparición de un limitado número de fragmentos de cerámica romana, a intramuros y extramuros del recinto murado (3). Su número es, hasta el presente, estadísticamente irrelevante como para aventurar la existencia allí de un grupo humano numéricamente significativo, lo que no excluye, por su misma presencia, la posibilidad de un asentamiento en un lugar más o menos próximo (4).

(1) En el corte 10 el muro de argamasa romana tiene una anchura máxima de, aproximadamente $1 \mathrm{~m}$., mientras que en el 11 es de unos $40 \mathrm{~cm}$., lo que, en todo caso, no debe corresponder a la anchura original, pues tiene aspecto de haber sido recortado.

(2) Las dimensiones de los sillares figurados con los que se disimulaba la estructura real del muro, tras haberlo enlucido, son substancialmente semejantes, en dos de sus medidas, a los conservados en otras zonas de la muralla, inequivocadamente fechadas en la segunda mitad del siglo XII.

(3) Se trata de algunos fragmentos de terra sigillata de forma imposible de determinar y de platos de los llamados de borde ennegrecido, cuya cronología, según Mercedes Vega ( «Cerámica común romana del Mediterráneo Occidental». Barcelona, 1973, págs. 49-53) se extiende desde el siglo I hasta los siglos II y III de nuestra era.

(4) Durante la tercera campaña de excavaciones llevada a cabo en la Alcazaba, el número de fragmentos de cerámica romana se vio nuevamente incrementado. Sin embargo, proporcionalmente se mantiene siempre una relación de neta inferioridad con respecto al material medieval, lo que, evidentemente, habla en favor de nuestra hipótesis. 
Mucho más clarificador que los vestigios arqueológicos ya descritos es un grupo de restos muy bien localizados y fácilmente identificables.

Uno de ellos lo componen dos sepulturas de hormigón romano situadas junto al recinto moderno de la ciudad, muy cercanas, especialmente una de ellas, a la hoy tapiada Puerta de Mérida.

El primero de los dos ejemplos (lám. III) lo constituye una simple fosa rectangular al pie del muro, por debajo de su arranque, de la que apenas queda intacto uno de los lados mayores y los arranques de los dos menores. La descripción de la casi totalidad de éstos y del que cerraba el conjunto se debió, con toda seguridad, a las canteras de cal excavadas al pie mismo de la fortificación, cuyas cortas forman hoy un profundo foso.

La segunda de las tumbas (lám. IV) está emplazada una treintena de metros más allá del muro, en una cota notablemente más baja que la descrita.

Sus características constructivas son semejantes en todo a las de la otra, aunque su estado de conservación, con ser mejor, es casi el mismo. No obstante, se conservan prácticamente intactos dos de sus lados contiguos y una pequeña escalera que desciente hasta el fondo, pavimentado con guijarros de río trabados con cal (5). El resto de la caja yace arrancada y derrumbada a unos pocos metros de distancia (6).

Resulta muy difícil reconocer el sistema utilizado para recubrir ambas fosas. Nada hay que permita suponerles una cubierta abovedada, aunque pueda admitirse la posibilidad de su existencia, y, probablemente, es factible pensar que ésta fuese plana, tanto si fue de lajas de piedra como si fue una única placa de hormigón. Es posible, incluso, que originalmente una de ellas destacase al exterior y estuviera edificada no en el subsuelo, sino sobre la superficie del mismo.

No se nos ha conservado resto alguno de ajuar, y dado lo escueto del tipo de construcción y de la forma de las tumbas, cualquier datación es, por el momento, harto arriesgada.

Hay, a pesar de todo, un aspecto más a considerar, relacionado con los motivos que indujeron a colocar allí los dos sepulcros. La relativa alineación de ambas edificaciones, en aparente relación con una puerta,

(5) Las dimensiones de la tumba son:

Anchura del muro: 0'60 m.

Largo del lado menor: $2^{\prime} 20 \mathrm{~m}$.

Longitud del lado mayor: 2'40 m.

Profundidad: $125 \mathrm{~m}$.

(6) Probablemente fue destruida en el momento de realizarse el acceso al fondo de la corta de la cantera, allí donde están hoy los viveros municipales. 
más o menos próxima, hace pensar inmediatamente en la existencia de una hipotética calzada cercana, lo que se ajusta con propiedad a uno de los aspectos típicos de la urbanística romana - y después de la hispanomusulmana-, consistente en colocar las necrópolis a ambos lados de las vías de comunicación que salían de las ciudades (7).

Naturalmente, en el caso de Badajoz parece un salto en el vacío pretender la existencia de vías, necrópolis e, incluso, puertas de muralla en una época en la que, como se desprende de todo el contexto, es problemática hasta la propia existencia de población. Hay, no obstante, un hecho concreto incuestionable: los accesos a una ciudad como Badajoz, literalmente abrazada por el Guadiana y su afluente el Rivillas, se han de hallar forzosamente condicionados a zonas del terreno muy concretas. Por esta razón, la llamada Puerta de Mérida de la fortificación del XVII se llama así, porque es el origen del camino que, a través del campo conocido como Prado de Mérida, conducía a esta ciudad. Todo hace, pues, suponer el paso, por aquel mismo lugar o sus cercanías, de un camino de unión entre ambas ciudades en las épocas medieval y antigua, cuando no existía el profundo barranco excavado por las susodichas canteras y la carretera general no seguía el trazado que ahora sigue.

El segundo grupo de restos arqueológico de probable origen romano se halla situado en la vega que se extiende al oriente de Badajoz, frente a la fortaleza medieval y junto al antiguo cauce del río conocido como Charco de Jamaco.

Destacan allí los restos de una alberca cuadrada (lám. V) cuyos muros de hormigón mantienen una altura media de aproximadamente dos metros y están sujetos por gruesos contrafuertes dispuestos en tramos irregulares (8). El interior, antes de convertirse en corral y cortársele un lienzo en el lado oriental para facilitar la circulación del ganado, fue sucesivamente revocado con almagre, aplicado sobre el cemento hidráulico con el que estuvo primitivamente enlucido. Aún pueden apreciarse vestigios de éste en diferentes zonas del muro.

Muy cerca de esta instalación y en presumible conexión con ella se conservan los restos de una represa edificada al nivel del antiguo curso

(7) Como ejemplo más cercano cf.: García Bellido, A.: «Mérida: la gran necrópolis romana de la salida del puente». ExcArqEsp., 11. Madrid, 1962 y ExcArqEsp., 45. Madrid, 1966; Bendala Galán, M.: "Las necrópolis de Mérida" en "Augusta Emerita. Actas del Simposio Internacional Conmemorativo del Bimilenario de Mérida». Madrid, 1976. Págs. 141-161.

(8) El número de contrafuertes es de cuatro por cada lado, siendo la distancia que los separa distinta en cada caso. Las medidas de cada uno de ellos son: 1'50 m. de frente por 1'00 m. de lado. La anchura del muro es de 0'90 m. y su longitud de 30 '10 m. aproximadamente. 
de agua. Sus restos, hoy totalmente dislocados y derribados, mantienen una cierta homogeneidad de alineación.

El conjunto de las dos obras debe relacionarse con una antigua instalación de riego cuyo funcionamiento resulta bastante oscuro y a la que no deben ser ajenos los que parecen apoyos de una noria, de fecha indudablemente más tardía, susbsistentes también en las inmediaciones.

Datar este conjunto supone, en principio, el mismo grado de dificultad que en los anteriores casos, dada la ausencia de otros elementos arqueológicos objetivos; pero, igual que en aquellos casos, el aspecto formal del material constructivo deja poco margen al error si se les supone edificados en época romana -más exactitud cronológica es imposible-. lo que no excluye una reutilización e, incluso, una modernización posteriores, con la incorporación de nuevos adelantos hidráulicos.

\section{CONCLUSION}

$\mathrm{Si}$, como apuntamos al comienzo del trabajo, no puede afirmarse en términos absolutos la existencia, en el área ocupada por la ciudad de Badajoz, de una población romana con características específicamente urbanas, no cabe abrigar dudas con respecto a la presencia, en sus inmediaciones, de restos arqueológicos cuya morfología es típicamente romana.

Ahora bien, eso no excluye de plano la presencia allí de un núcleo de población más o menos grande, cuya localización es, hoy por hoy, muy difícil de precisar. Personalmente creemos que, de haberlo habido, no debió hallarse su centro en la cumbre del cerro que sirve de asiento a la Alcazaba, sino, más bien, en sus laderas. Ello explicaría fácilmente la ausencia de hallazgos en un área cubierta por el caserío desde muy antiguo.

Es evidente, sin embargo, que las óptimas condiciones agrícolas de la zona contribuyesen a dispersar los grupos humanos por toda el área de la vega del río y a crear pequeñas concentraciones humanas dedicadas a las labores agrícolas y ganaderas. La existencia, en las cercanías del núcleo urbano actual, de instalaciones hidráulicas, vendría a certificar esta teoría.

Desde un punto de vista estrictamente militar, no conviene olvidar las las excelentes cualidades defensivas del Cerro de la Muela, especialmente propicio para servir, adecuadamente fortificado, de atalaya, en tiempo de paz, y de refugio, en momentos de actividad guerrera. En cualquier caso, toda conclusión precipitada es peligrosa, puesto que, si descartamos la presencia de unas fortificaciones tan imponentes como las medievales conservadas, es factible la existencia de vestigios de esta naturaleza en el mismo lugar ocupado hoy por el Hospital Militar. 
No se trata, a pesar de todo lo expuesto, de aventurar teorías más o menos fundamentadas. La óptica, quizás deformada, con que se ha elucubrado sobre el pasado romano de la ciudad de Badajoz, puede variar de un modo apreciable, de hecho ya lo está haciendo, según vaya corrigiéndose con el incremento de estudios arqueológicos sistemáticos.

Por ello es conveniente aguardar la confirmación o el desmentido con que los resultados arqueológicos objetivos iluminarán el pasado de la que, andando el tiempo, pasará por ser fundación hispano-musulmana y llegará a convertirse en cabeza del reino aftasí.

Lo demás, con ser verosímil, no pasa de estar situado en el campo de las puras hipótesis de trabajo pendientes de ratificación. 


\section{INDICE DE LAMINAS}

Lámina I. 1. Corte 10. Vista desde el Oeste.

Lámina II. 2. Corte 11. Vista desde el Este.

Lámina III. 3. Tumba romana al pie de la Puerta de Mérida.

Lámina IV. 4. Tumba romana enfrente de la Puerta de Mérida. Vista desde el Norte.

Lámina V. 5. Vista aérea de la alberca romana. 
LAMiNA I.

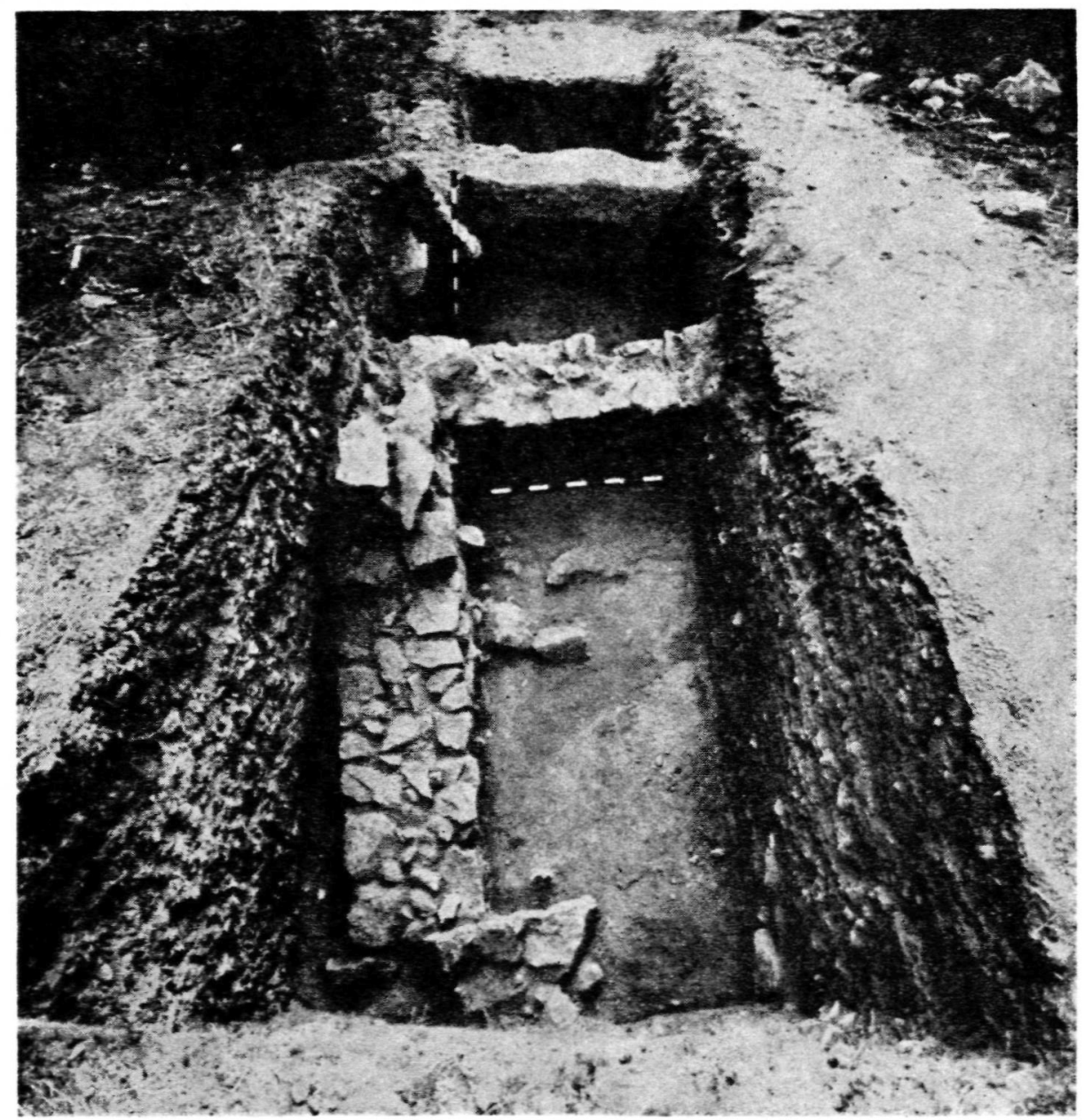

1. Corte 10. Vista desde el Oeste (Foto: J. Latova.) 
LÁMINA II.

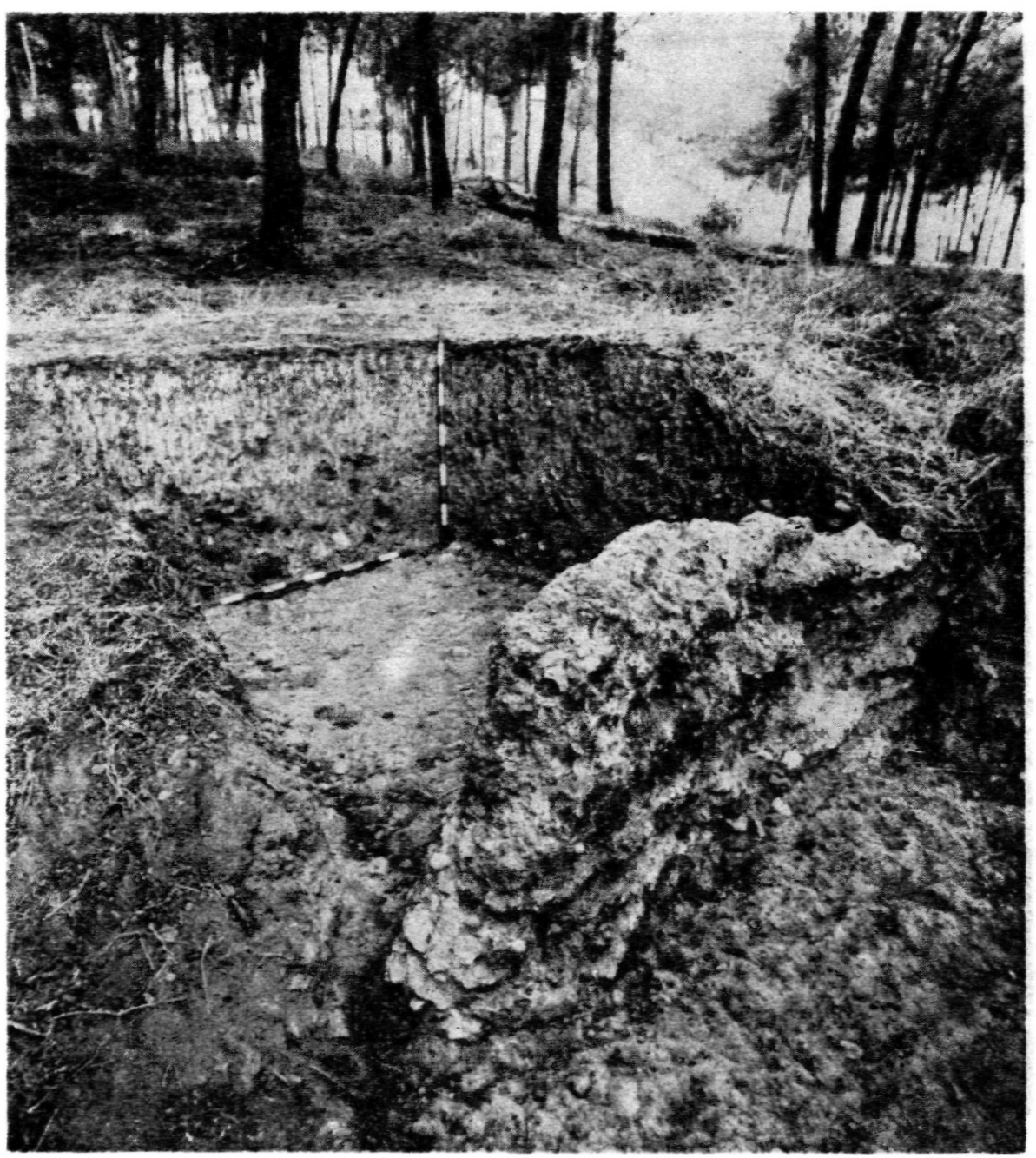

2. Corte 11. Vista desde el Este (Foto: J. Latova.) 
LÁMINA III.

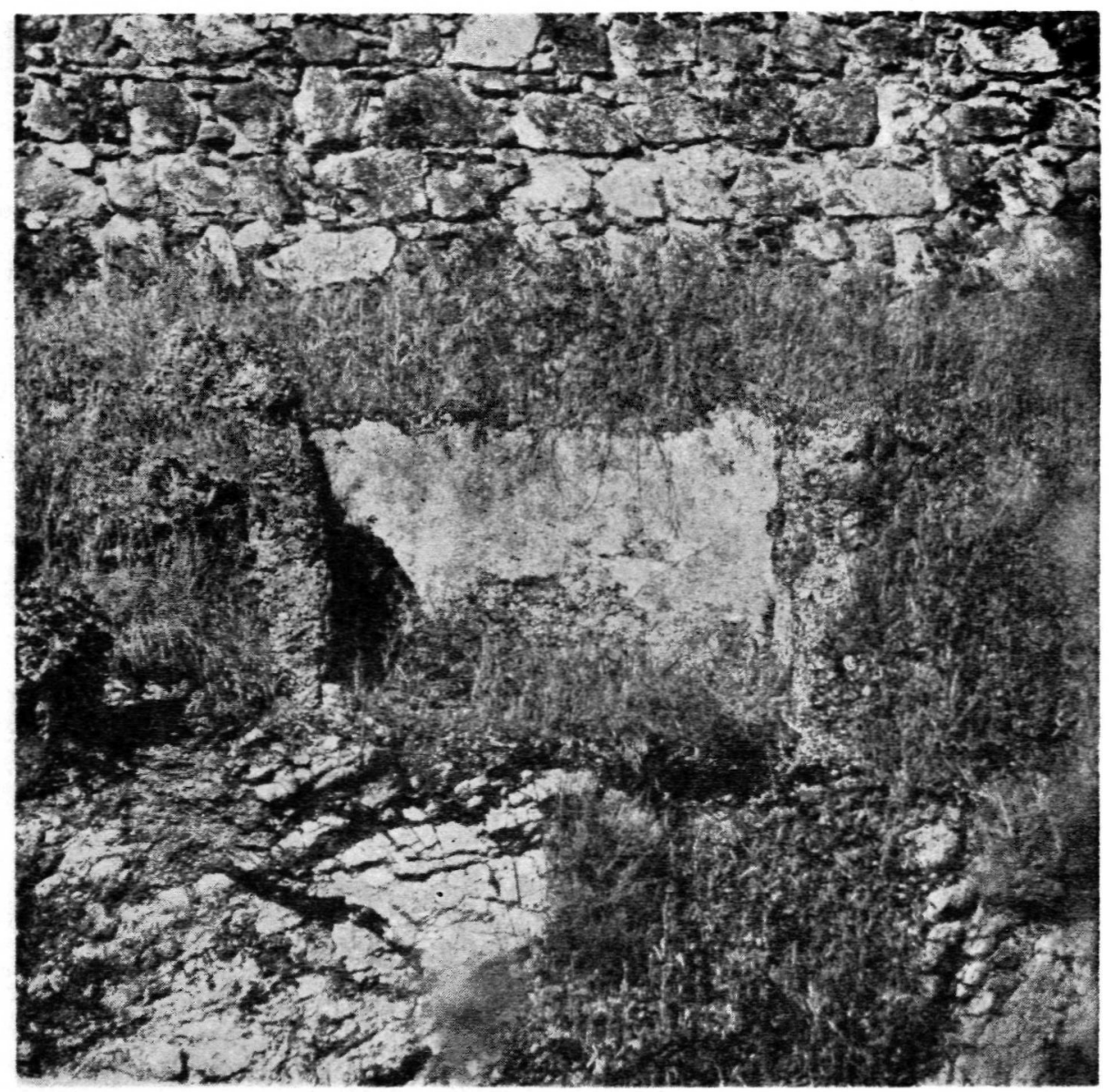

3. Tumba romana al pie de la Puerta de Mérida (Foto: J. Latova) 


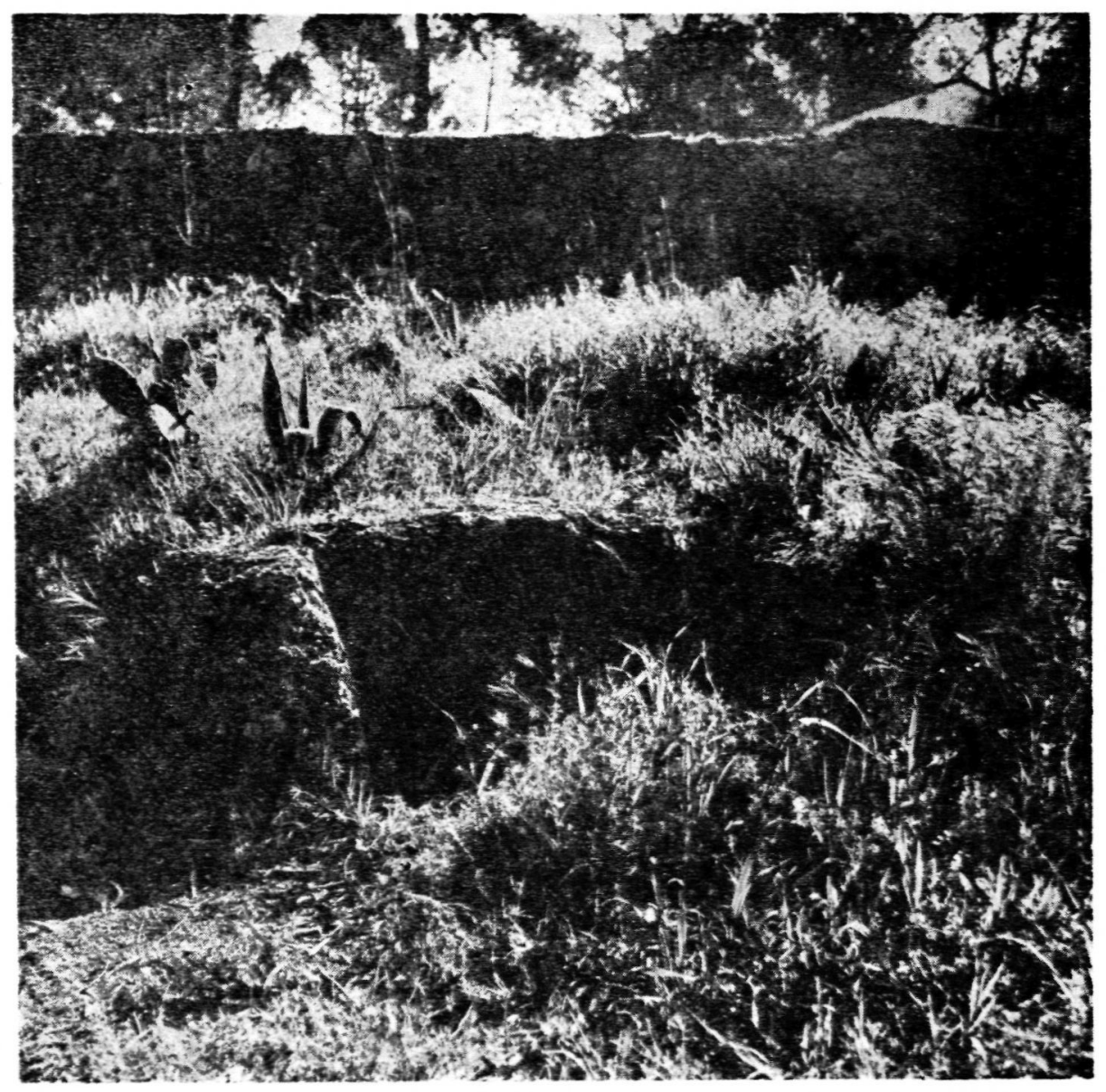

4. Tumba romana enfrente de la Puerta de Mérida. Vista desde el Norte (Foto: J. Latova.) 
LÁMINA V.

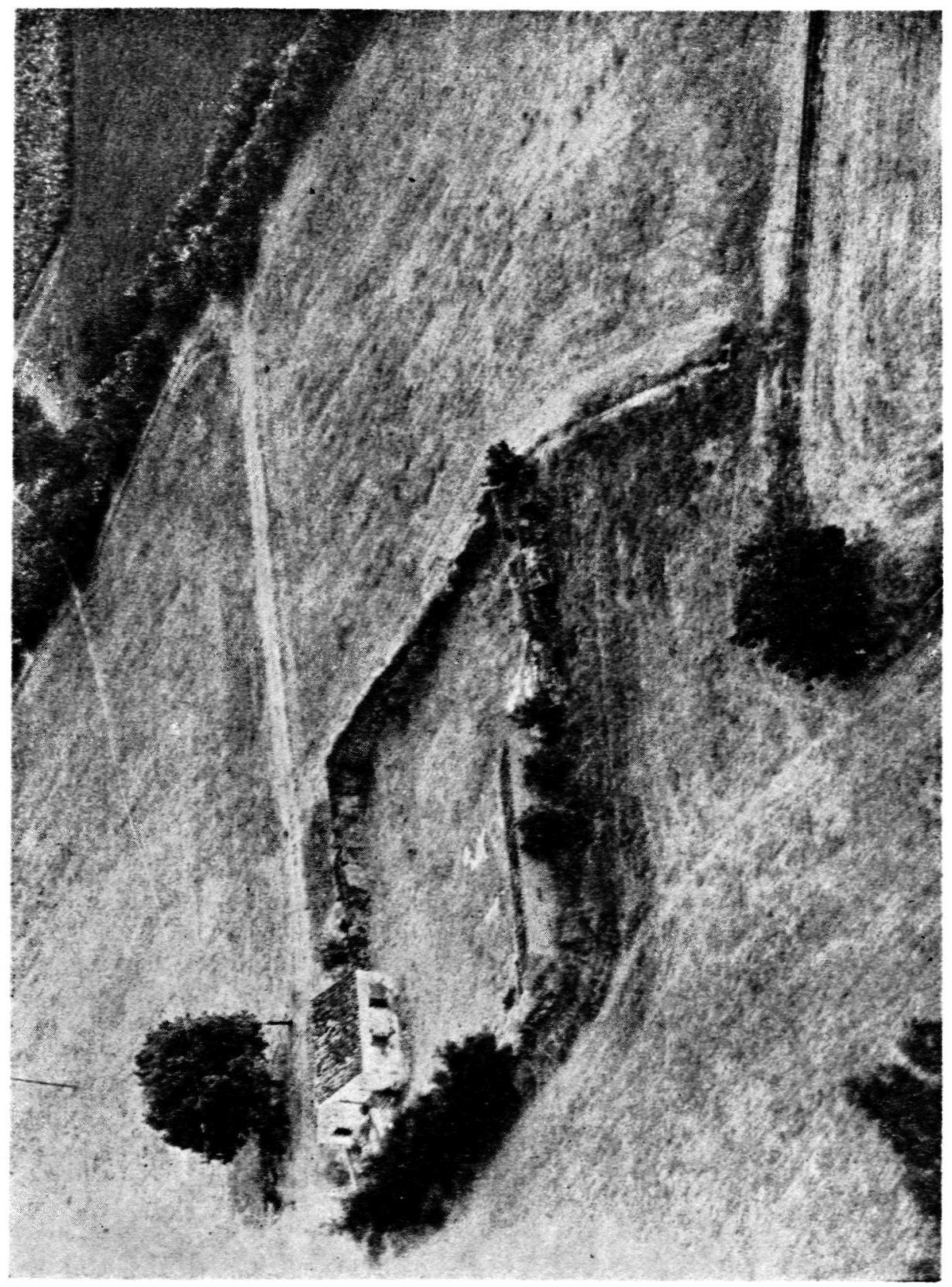

5. Vista aérea de la alberca romana (Foto: J. Latova.) 